\title{
BRIQUETTE BURNER
}

\author{
Abel Christena Francis ${ }^{1}$, Akhiljith $\mathrm{A}^{2}$, Allen Alexander ${ }^{3}$, Bibin K Baby ${ }^{4}$ \\ ${ }^{1} B$-Tech, Mechanical Engineering, Saintgits College of Engineering, Kerala \\ ${ }^{2} B$-Tech, Mechanical Engineering, Saintgits College of Engineering, Kerala \\ ${ }^{3} B$-Tech, Mechanical Engineering, Saintgits College of Engineering, Kerala \\ ${ }^{4}$ B-Tech, Mechanical Engineering, Saintgits College of Engineering, Kerala
}

\begin{abstract}
With the present day large dependence and rise in price of cooking gas and also the less availability of alternative fuel like firewood which could cause pollution, there comes, the need of a more efficient fuel or burner. So our idea deals with the building of a domestic burner which serves as a cooking stove which is exclusively working on an alternative fuel.

The fuel used for this burner is compressed sawdust (Biomass Briquettes). Briquetting of residues take place with the application of pressure, heat and binding agent on the loose materials to produce the briquettes. Briquettes are conventionally used in large industries as a fuel for boilers and gasifiers. Briquettes are not used for domestic purposes due their poor ignitability. Our aim is to develop a domestic burner that would easily ignite these briquettes and improve the efficiency of the heat obtained which can be used for domestic cooking. Our design is intended to reduce dangerous exposure to unnecessarily high levels of smoke, avoiding the illnesses by these smoke, while maintaining desirable aspects of current cooking techniques, including reliability, simplicity and low cost. The burner of our design can suitably and most efficiently burn the saw dust briquettes with additional facility of maintaining heat. This burner contains an insulated combustion chamber with provision for adequate air supply. The combustion chamber design is to concentrate the flame and heat to the cooking utensils for maximum efficiency.
\end{abstract} - ***.

\section{INTRODUCTION}

Three billion people, approximately half the world's population, depend on biomass fuels (wood, crop residue, animal dung, etc) as their primary domestic energy source (WHO 2002). Often, the combustion of these fuels is done indoors over open fires with little or no means of ventilation. Extended exposure to biomass emissions significantly increases the risk of acute respiratory infections, chronic bronchitis, and obstructive pulmonary disease (Bruce, Perez-Padilla et al. 2002).

Open fires emit substantial amounts of pollutants, including respirable particles, carbon monoxide, nitrogen and sulphur oxides, and benzene. The small particles in wood-smoke can bypass the normal body defence mechanisms and penetrate deep into the alveoli of the lungs, harming the respiratory system and there have been clear links made between their inhalation and disease. These smoke problems particularly and considerably affect women and young children who, in developing nations are typically responsible for the domestic duties in the home.

In addressing these problems, one solution is to utilise the available biomass residues. But the there are many problem while using the biomass in the raw form. Hence its solution is Briquetting. Biomass briquetting is the densification of loose biomass material to produce compact solid composites of different sizes with the application of pressure. The final solid composites are called Briquettes. Briquetting of residues takes place with the application of pressure, heat an binding agent on the loose materials to produce the briquettes.
Following are the advantages of briquette:

- This is one of the alternative methods to save the consumption and dependency on Fuel wood and LPG

- These are easy to handle, transport and store.

- They are uniform in size and quality.

- The process helps to solve the residual disposal problem.

- The process assists the reduction of fuel wood and deforestation.

- Indoor air pollution is minimized.

\section{STOVE THEORY}

Adequate draft and a proper air-to-fuel ratio ensure a more complete and efficient combustion process. A hotter fire is also more effective at consuming combustible gases. Proper insulation around the combustion chamber reduces heat loss, allowing the fire to burn at higher temperatures. Stove heat transfer efficiency describes the amount of energy absorbed by the cook pot relative to the amount of energy released by the combustion process. When carefully controlled, even an open fire is capable of high combustion efficiency. However, in an open fire, radiation is the main mechanism of heat transfer, and approximately $20-40 \%$ of its input energy is lost to the atmosphere as hot gas emissions. Utilizing these hot gases through effective convective heat transfer can significantly improve thermal efficiency. In an improved stove convection is the primary method of energy transfer between the moving combustion gases and the stationary surface of the cook pot. Convection consists of energy transfer through bulk fluid motion, advection, and the arbitrary motion of fluid molecules, conduction. Advection is the more effective mechanism of energy transfer and is 
proportional to the fluid velocity. Therefore, design features of improved stoves seek to maximize the velocity of the combustion gases as well as the pot surface area in contact with these gases.

\section{METHODOLOGY}

\subsection{Introduction}

For understanding and studying the burning characteristics of the biomass fuel such as ignitability, heat content, flame production, smoke generation, air flow, ash production, an experiment was conducted using a biomass briquette of $60 \mathrm{~mm}$ diameter in a water boiling test setup on a traditional "Alua-stove".

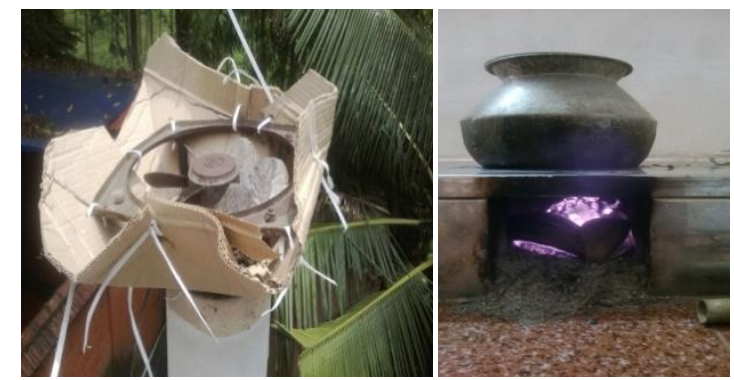

Fig. 1 Experimental setup

Briquettes (60mm diameter), coconut shell, kerosene, vessel filled with water $\left(10^{-3} \mathrm{~m}^{3}\right)$, stopwatch, exhaust fan, regulator, thermometer. This setup is shown in Figure 1.

\subsection{Experiment Setup and Procedure:}

- An exhaust fan was installed at the top of the chimney to produce an induced draught. A regulator was connected to the exhaust circuit to regulate the rpm of the exhaust fan and thereby controlling the heat flow.

- A regulator was connected to the exhaust circuit to regulate the rpm of the exhaust fan and thereby controlling the heat flow.

- Biomass briquette sprayed with kerosene is fed to the combustion chamber. Coconut is first burned and is then fed into the combustion chamber for the initial burning of the briquette.

- $\quad$ After attaining the proper burning of the briquette, a vessel filled with water $\left(10^{-3} \mathrm{~m}^{3}\right)$ was placed on the pot stand.

- A thermometer fitted on the vessel was used to observe the raise in temperature.

- A stop watch was used to measure the time for temperature rise from $31^{\circ} \mathrm{C}-90^{\circ} \mathrm{C}$.

\subsection{Inference}

- The initial delay of the burning of the biomass briquette was due to insufficient supply of air.

- Flame has a natural tendency to flow in the direction of air, so at high speed the flame was in the direction of air flow.
- $\quad$ Briquettes have a higher calorific value compared to fire wood so the time for the boiling of water was less when briquette was used as a fuel.

- When compared to fire wood briquettes have less moisture content hence the smoke produced was less,

- $\quad$ Since a blue flame was observed it can be inferred that the impurities present in the given sample was less and has higher heat value.

\section{DESIGN CONSIDERATIONS}

From the literature survey and the experiment conducted we had come to the following conclusions regarding the main criteria required while designing briquette-burner.

- Heat concentration- Heat should be concentrated for maximum thermal efficiency so that the heat produced during the combustion of the fuel is being transferred more efficiently to the cooking port when compared to conventional burners.

- Induced Drought- An induced draught should be provided as sufficient air is required for complete combustion.

- Regulator- A regulator should be provided on the fan of the induced draught to control the air flow which in turn controls the heat flow.

- Insulation- While designing a biomass burner the heat lost to the surroundings by means of heat transfer such as conduction, convection and radiation should be minimised. Therefore necessary materials are selected for making the combustion chamber for proper insulation so that the heat can be utilized fully for cooking purposes.

- Grate- Grate should be provided for the proper placing of biomass fuel during burning.

- $\quad$ Sprayers- Since the initial burning of the biomass briquettes are hard so sprayers are provided. Flammable fuels such as kerosene, diesel, petrol etc are sprayed in the form of fine droplets on the surface for the initial burning.

- Initial igniter- Initial igniter should be provided for initial burning of the fuel.

- Pot stand- for the proper utilisation of the heat that is being generated during the combustion of the biomass fuel, a minimum of two port stand should be provided.

- Chimney- The smoke that is being produced during the burning of bio mass should be guided through the chimney. The induced draught that is been installed in the chimney creates a suction that would effectively help remove the smoke.

- Soot collector- A soot collector should be placed in the passage through the chimney to collect large particles of ash. The soot collector can be removed and disassembled for cleaning purpose.

- Ash pit- An ash pit is provided at the bottom of the burner to collect the ash that would be formed when the biomass is burnt. The position should be such that it provides the additional benefit of combustion chamber insulation. 
- Primary air hole- Primary air hole is provided that would provide the necessary air for the complete combustion of the fuel.

- Secondary air hole- Secondary air holes are provided for adequate air supply for combustion.

\section{DESIGN AND TESTING}

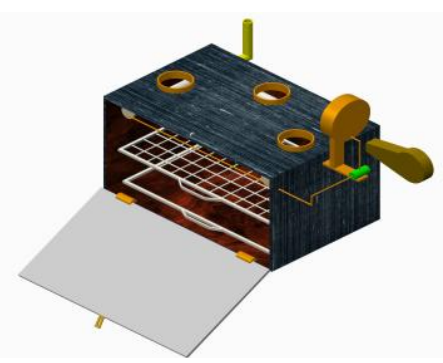

Fig. 2 Final Design

The water boiling test is a well-known test, which has been used previously. It measures the time it takes a given quantity of fuel to heat and boil a given quantity of water.The procedures outlined in the Water Boiling Test (WBT) from the Partnership for Clean Indoor Air (2007) were used to evaluate the thermal performance of the stove.

The testing is done in two phases:

\section{- $\quad$ Cold Phase Testing}

In this phase, the tester begins with the burner at room temperature and uses a pre-weighed bundle of briquette to heat a measured quantity of water to $90^{\circ} \mathrm{C}$ in a standard pot.

\section{- $\quad$ Hot Phase Testing}

The second phase immediately follows the first test, while the burner is still hot. In order to test the prototype, cold phase and hot phase testing was done on the briquette burner. The result was tabulated which is shown in Table 1 the table shows that hot phase testing boils water $1.5 \mathrm{~min}$ earlier than cold phase testing.

Table 1 Result of Cold phase and Hot Phase testing

\begin{tabular}{|l|l|l|l|}
\hline \multicolumn{2}{|l|}{ Cold Phase Testing } & \multicolumn{2}{l|}{ Hot Phase Testing } \\
\hline $\begin{array}{l}\text { Time } \\
(\mathrm{min})\end{array}$ & Temperature $\left({ }^{\circ} \mathrm{C}\right)$ & $\begin{array}{l}\text { Time } \\
(\mathrm{min})\end{array}$ & Temperature $\left({ }^{\circ} \mathrm{C}\right)$ \\
\hline 0 & 32 & 0 & 32 \\
\hline 3 & 39 & 3 & 41 \\
\hline 6 & 48 & 6 & 51 \\
\hline 9 & 58 & 9 & 63 \\
\hline 12 & 69 & 12 & 71 \\
\hline 15 & 80 & 15 & 85 \\
\hline 18 & 90 & 16.5 & 90 \\
\hline
\end{tabular}

Quantity of Fuel used: $1 \mathrm{~kg}$

Amount of water: $10^{-3} \mathrm{~m}^{3}$

The result shows that the time taken by the burner during hot phase testing is lesser than that in cold phase testing. This less time is due to the presence of heated air.

\subsection{Analysis with Wood and Briquette in Aluva} Stove

Quantity of Fuel used: $1 \mathrm{~kg}$

Amount of water: $10^{-3} \mathrm{~m}^{3}$

Table 2 Results of wood and briquette in Aluva stove

\begin{tabular}{|l|l|l|l|}
\hline \multicolumn{2}{|l|}{ Briquette } & \multicolumn{2}{l|}{ Firewood } \\
\hline $\begin{array}{l}\text { Time } \\
(\mathrm{min})\end{array}$ & Temperature $\left({ }^{\circ} \mathrm{C}\right)$ & $\begin{array}{l}\text { Time } \\
(\mathrm{min})\end{array}$ & Temperature $\left({ }^{\circ} \mathrm{C}\right)$ \\
\hline 0 & 31 & 0 & 31 \\
\hline 3 & 37 & 3 & 35 \\
\hline 6 & 46 & 6 & 43 \\
\hline 9 & 55 & 9 & 51 \\
\hline 12 & 62 & 12 & 59 \\
\hline 15 & 73 & 15 & 67 \\
\hline 18 & 85 & 18 & 77 \\
\hline 20 & 90 & 21 & 84 \\
\hline & & 22 & 90 \\
\hline
\end{tabular}

A comparison between wood and briquette was estimated shown in Table 2. This comparison will help to prove that briquette is better than wood. Presently available stove is Aluva stove so the first experiment was conducted in Aluva stove to get the time taken to boil the water to $90^{\circ} \mathrm{C}$. From the Table 2 it can be inferred that wood takes $22 \mathrm{~min}$ and briquette takes $20 \mathrm{~min}$ only to boil same quantity of water with same quantity of fuel.

The result shows that briquette is a better option as a fuel in Aluva stove.

\subsection{Analysis with Wood and Briquette in Burner}

This is a performance which is done to evaluate the performance of the briquette burner with both the wood and briquette. The result obtained was tabulated in Table 3 which shows that briquette takes water to boil in 18 minutes while wood takes 20 minutes to boil to $90^{\circ} \mathrm{C}$.

Table 3 Comparison of Wood and Briquette in Briquette Burner

\begin{tabular}{|l|l|l|l|}
\hline \multicolumn{2}{|l|}{ Briquette } & \multicolumn{2}{l|}{ Firewood } \\
\hline $\begin{array}{l}\text { Time } \\
(\text { min })\end{array}$ & Temperature $\left({ }^{\circ} \mathrm{C}\right)$ & $\begin{array}{l}\text { Time } \\
(\min )\end{array}$ & Temperature $\left({ }^{\circ} \mathrm{C}\right)$ \\
\hline 0 & 32 & 0 & 32 \\
\hline 3 & 39 & 3 & 36 \\
\hline 6 & 48 & 6 & 45 \\
\hline 9 & 58 & 9 & 54 \\
\hline 12 & 69 & 12 & 63 \\
\hline 15 & 80 & 15 & 76 \\
\hline 18 & 90 & 20 & 90 \\
\hline
\end{tabular}

Quantity of Fuel used: $1 \mathrm{~kg}$ and Amount of water: $10^{-3} \mathrm{~m}^{3}$ 


\subsection{Comparison of Briquette Burner with LPG}

In the present market of India, briquette is available at the rate of Rs. 6 per kilogram. For a family of four members the average consumption of briquette is approximately $60 \mathrm{~kg}$ for two months when used in briquette burner on a rough scale. So the cost is Rs. 360 with a heat value of $1080 \mathrm{MJ}(\mathrm{CV}=$ $18 \mathrm{MJ} / \mathrm{kg}$ ) in two months. But if we take the case of LPG cylinder of $14.6 \mathrm{~kg}$ this can be consumed for maximum of two months has a total heat value of only $660 \mathrm{MJ}(\mathrm{CV}=$ $45 \mathrm{MJ} / \mathrm{kg}$ ) which cost Rs. 400. So taking the cost and heat value factor briquette burner is good. But for the reason of more reliability of LPG makes it more preferable.

\section{ANALYSIS}

\subsection{Aim}

1. To understand the heat distribution in the three ports.

2. To determine the flow vector of air and heat.

3. To find the efficiency of each port.

4. To get a clearer picture of motion heat and air.

\subsection{Methodology Adopted}

The analysis was conducted using Solid Works - 2011 .

\subsubsection{Thermal Analysis}

The Boundary Conditions set for the analysis are

1. Static pressure was set as 1 atm at the top of the outlet ports.

2. Maximum temperature in the combustion chamber was set as $500 \mathrm{~K}$.

\subsubsection{Flow Analysis}

The Boundary Conditions set for the analysis were as follows

1. Static pressure was set as 1 atm at the top of the outlet ports.

2. Maximum Temperature in the combustion chamber was set as $500 \mathrm{~K}$

Input Data: Discharge from each hole $=0.4219 \times 10^{-4} \mathrm{~kg} / \mathrm{s}$

\subsection{Heat Concentration}

Analysis was run for a physical time of 3600s. The Figure 3 shows the result of analysis of heat concentration.
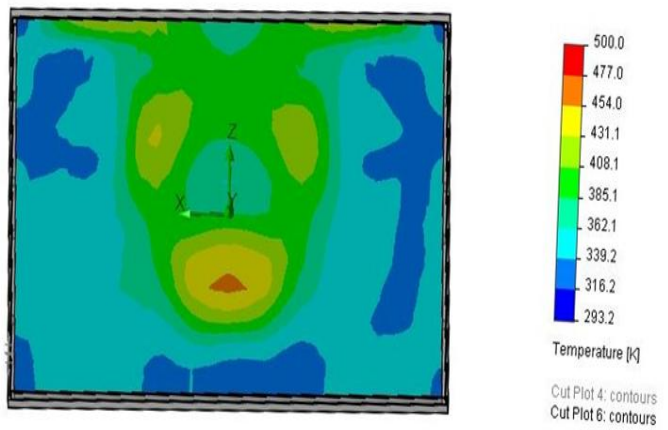

Fig. 3 Heat Concentration
It was observed that maximum heat concentration is at the central port. The red region is the region of maximum temperature $\mathrm{K}$. The green region is at around $400 \mathrm{~K}$. the blue region is the lowest temperature of $300 \mathrm{~K}$ which is due to the air supplied through the pipe in that region.

\subsection{Heat and Air Flow Lines}

The analysis of air and heat flow is carried out and the result obtained is shown in the Figure 4 where blue lines indicate air flow and red lines indicate heat flow.

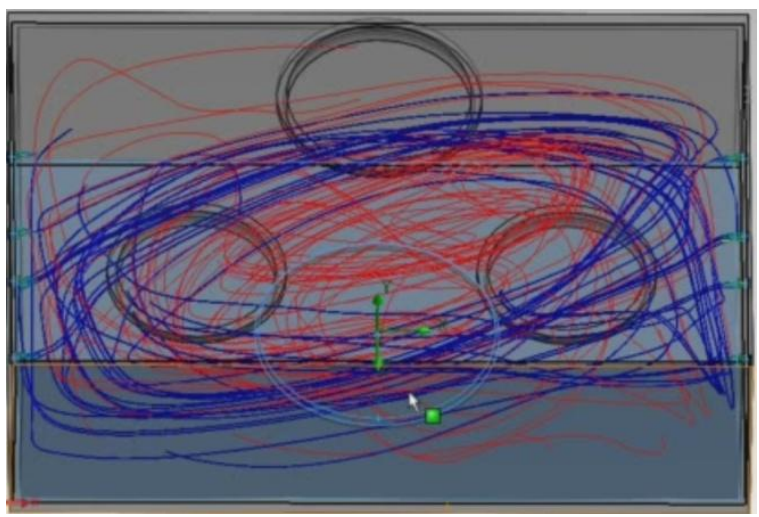

Fig. 4 Heat and Air Flow Lines

\subsection{Heat Flux Lines}

There are a total of 19 heat flux lines moving out through the outlet as shown in Figure 5.

9 flux lines at the centre $(47.36 \%)$

5 flux lines at the right side $(26.31 \%)$

5 flux lines at the left side $(26.31 \%)$

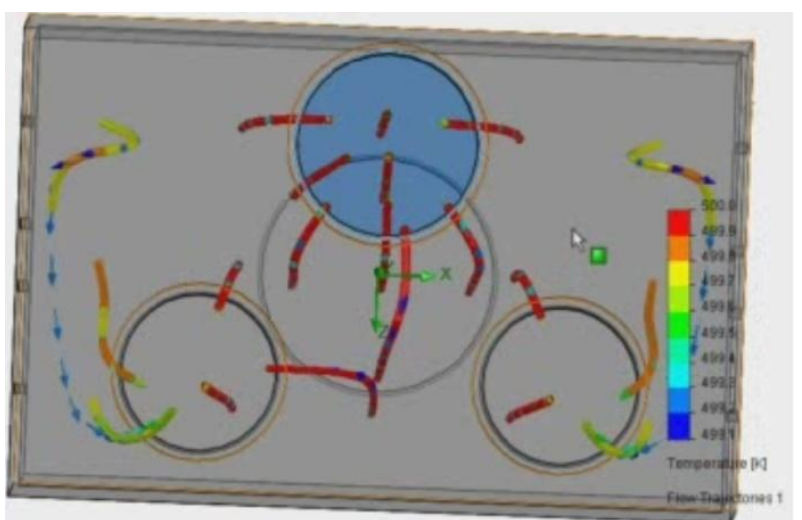

Fig. 5 Heat Flux Lines

\section{CONCLUSIONS}

Briquettes can be made from waste biomass, this can help in reducing the pressure on the forest resources for fuel and being in the compressed form, the smoke and ash content is comparatively less while burning briquettes which results in low pollution. So utilizing these briquettes in an efficient burner helps in better combustion of these fuels. The use of firewood as a fuel consumes a lot of time for igniting and produces large amount of smoke which may be irritating. So this burner also helps in reducing such disadvantage of using conventional Chula system. Another advantage of replacing 
firewood with briquette is that the amount of consumption of briquette is comparatively much lower than firewood and retains heat for a longer period with less amount of ash deposit. (For every $1 \mathrm{~kg}$ of firewood only $0.7 \mathrm{~kg}$ of briquette is required).

From the experiments conducted, the burner acquired its maximum temperature of $90^{\circ} \mathrm{C}$ for a time of 16.5 minutes which is less than the time taken during the cold phase testing for 18 minutes. The briquette burns effectively in the Briquette Burner than the Aluva stove, since it takes only 18 minutes to reach a temperature of $90^{\circ} \mathrm{C}$ than 20 minutes in Aluva Stove. Since the actual discharge of blower was found to be higher than the required stoichiometric air for the complete combustion of briquette, thus combustion takes place inside the burner.

The analysis conducted on solid works shows that, maximum heat flux of $47.36 \%$ is at the central port and the other two have an equal heat flux of $26.31 \%$. The use of glasswool for insulation was found to be effective and being lighter than clay or ceramics the burner could be made portable.

\section{REFERENCES}

[1] Maninder1, Rupinderjit Singh Kathuria2, Sonia Grover3; Using Agricultural Residues as a Biomass Briquetting: An Alternative Source of Energy ; IOSR Journal of Electrical and Electronics Engineering (IOSRJEEE) ISSN: 2278-1676 Volume 1, Issue 5 (July-Aug. 2012), PP 11-15

[2] 1J. O. Chaney, M. J. Clifford and R. Wilson; An experimental study of the combustion characteristics of low density biomass briquettes ; Fuel processing technology, Progress in Energy and Combustion Science, 2010, 30,2, 219-230

[3] V. I. Umogbai and J. G. Orkuma; Development and Evaluation of a Biomass Stove; Journal of Emerging Trends in Engineering and Applied Sciences (JETEAS) 2 (3): 514-520

[4] Jaan Kersa, Priit Kulua, Aare Aruniita, Viktor Laurmaaa, Peter Križanb,LubomirŠoošb and ÜloKaskc; Determination of physical, mechanical and burning characteristics of polymeric waste material briquettes; Estonian Journal of Engineering, 2010, 16, 4, 307-316 doi: 10.3176/eng.2010.4.06

[5] Markson, I.E, Akpan, W.A, Ufot, E; Determination of Combustion Characteristics of Compressed Pulverized Coal-RiceHusk Briquettes ; International Journal of Applied Science and Technology, Vol. 3 No. 2; February 2013

[6] D.B. Yahaya and T.G. Ibrahim ; Development of rice husk briquettes for use as fuel; Research Journal in Engineering and Applied Sciences 1(2) 130-133 ; 2012 